\title{
Anti-terrorism measures in South Africa: Suspicious transaction reporting and human rights
}

\author{
Mzukisi Niven Njotini* \\ Senior Lecturer, Department of Jurisprudence, College of Law, University of \\ South Africa
}

\begin{abstract}
Summary
Terrorism has become a serious risk. Two factors exacerbate this threat: The first is the challenge of finding a definition suited to the terrorism phenomenon; the second is linked to the difficulty of detecting this crime. As it is accepted that terrorism causes human distress and suffering, and weakens the basic rights and freedoms of people, measures are taken to alleviate this scourge. In this article, mechanisms that relate to the duty to report transactions - so-called suspicious transaction reports - are analysed. It is accepted that these should operate in frameworks that show respect for human rights, for example, the rights to privacy and confidentiality. Accordingly, suspicious transactions should be reported reasonably and must be justifiable in the circumstances.
\end{abstract}

Key words: Cyberspace; cyber-terrorism; suspicious transactions reporting; suspicious transactions records

\section{Introduction}

Terrorism poses a grave threat to society. It is reported that the consistent increase in terrorist acts continues to be a major drawback to countries' development. ${ }^{1}$ In Africa alone, four terrorist groups, namely, al-Shabaab, Boko Haram, al-Qa'ida and the Islamic State of

\footnotetext{
* $\quad$ LLB (Vista), LLM (South Africa); Njotim@unisa.ac.za. This article is adapted from a paper that was presented at a conference, Liberty and Security in the Age of Terrorism, Morehead State University in Lexington, Kentucky, United States of America, 21-24 October 2010.

1 United States Department of State 'Country reports on terrorism 2013 - Executive summary' (2014) http://www.state.gov/documents/organization/225050.pdf (accessed 19 February 2015).
} 
Iraq and the Levant (ISIL), are identified as sources of terrorist activities. $^{2}$ The terrorist threats that these groups pose are not limited to activities that occur in the real physical world; for example, the bombing of physical infrastructures. They also extend to those that occur in virtual circles (cyberspaces), that is, cyber-terrorism. ${ }^{3}$ In this instance, the activities are designed to weaken and attack the security and stability of a country's critical information infrastructures (Clls). ${ }^{4}$

Challenges exist in relation to describing terrorism with precision, ${ }^{5}$ and the cumbersome nature of processes to investigate this occurrence. This has led some to compare terrorism to human distress and unhappiness. ${ }^{6}$ Terrorism threatens the fundamental rights and freedoms of people. Examples of these rights and freedoms are,

2 United states Department of State (n 1 above) 11. See also the case of $S v O k a h$ [2013] ZAGPJHC 75, where a South African citizen was convicted on 13 charges of having been involved in and/or leading in the carrying out of the activities of a terrorist group called Movement for the Defence of the Niger Delta.

3 Denning defines cyber-terrorism as the 'convergence of terrorism and cyberspace. It is generally understood to mean unlawful attacks and threats of attack against computers, networks, and the information stored therein when done to intimidate or coerce a government or its people in furtherance of political or social objectives. Further, to qualify as cyber-terrorism, an attack should result in violence against persons or property, or at least cause enough harm to generate fear.' See DE Denning 'Cyber-terrorism testimony before the Special Oversight Panel of Terrorism' (2000) http://bit.ly/16rUw3i (accessed 14 January 2012).

4 MN Njotini 'Identifying critical data and databases - A proposal for a risk-based theory of implementing Chapter XI of the ECT Act' (2013) 34 Obiter 96 97-98. Clls encompass information security structures that are designed to protect information or data that are recoded or kept or stored on computers or computer software. See NK Katyal 'Criminal law in cyberspace' (2001) 149 University of Pennsylvania Law Review 1003-1006.

5 It is generally difficult to provide an accurate definition of the term 'terrorism'. This difficulty leads some to resort to phrases such as 'you know it (terrorism) when you see it' (S Sloan Terrorism: The present threat in context (2006) 19). Notwithstanding the above-mentioned difficulty, attempts are made to define the term. On the one hand, terrorism is the 'pre-meditated or repeated use of actual violence or threat to use violence against innocent civilians in order to achieve an objective or acts of reprisal' (B Raman Terrorism: Yesterday, today and tomorrow (2008) 1-6). Conversely, terrorism is an 'illegal use of extreme force and violence for the purpose of coercing a governmental entity or population to modify its philosophy and direction' (WE Dyson Terrorism: An investigator's handbook (2012) 5). It is submitted, however, that not all acts of terrorism are directed against humans or civilians. Contemporary terrorism acts particularly compromise or threaten to compromise a country's essential or key information infrastructures, for example, data and databases. Therefore, the article avers that the definitions above are inadequate to cover novel forms of terrorism or terrorist occurrences, for example, cyber-terrorism. For the aforementioned reason, the term 'terrorism' is described as meaning any act or conduct that directly or indirectly causes death, serious bodily injury or discomfort to an inhabitant or any other person or that is intended to intimidate a population, or to compel a government or an international organisation to carry out or to abstain from carrying out any act.

6 HO Agarwal International law and human rights (2003) 613-614. See also Office of the United Nations High Commissioner for Human Rights (OHCHR) 'Human rights, terrorism and counter-terrorism' http://www.ohchr.org/Documents/Publi cations/Factsheet32EN.pdf (accessed 10 May 2013) (OHCHR Fact Sheet 32). 
amongst others, the rights to life, physical integrity and personal freedom. ${ }^{7}$ These rights and freedoms are significant in that they provide 'appropriate protections and benefits for all people of the world'. ${ }^{8}$ They entitle the holders to claim an exercise free from interference by other persons or governments. ${ }^{9}$ However, uncertainty persists regarding the proper approach in the fight against terrorism. It is asked whether the fight against terrorism could be reconciled with the protection of human rights. For example, is a suspension of human rights and certain constitutional guarantees justified when fighting the scourge of terrorism? ${ }^{10}$ It is further asked whether it is fair and just to apply the principles of 'fair treatment' to a criminal in cases where this application disregards the concerns of victims. ${ }^{11}$ In other words, is it logical or rational to apply the principles of fair treatment to a terrorist who is not part of the 'law-abiding majority who play by the rules and think (that) others should too'? ${ }^{12}$

The article examines these questions at length. It is investigated whether human rights should be suspended when dealing with terrorism. This scrutiny is premised on the fact that the success(es) of an anti-terrorism framework generally depend on the success(es) of a culture $^{13}$ of human rights. ${ }^{14}$ Internationally, human rights measures are contained, inter alia, in the Charter of the United Nations of 1945 (UN Charter of Rights) and the Universal Declaration of Human Rights of 1948 (Universal Declaration). ${ }^{15}$ Having accepted the need to reconcile the fight against terrorism with a human rights culture, it is acknowledged that the measures to alleviate terrorism are plentiful. There are measures to criminalise terrorism, to provide for the confiscation and forfeiture of the proceeds of terrorism, and to prevent terrorism. In this article, transaction reporting is identified as an essential mechanism to prevent terrorism. It is argued that a

7 HO Agarwal (n 6 above) 613-614.

8 T Ward et al 'Human rights and the treatment of sex offenders' (2007) 19 Sex Abuse 195

$9 \quad$ Ward et al (n 8 above) 198.

10 M Ignatieff The lesser evil: Politics in an age of terror (2004) vii.

11 T Blair 'Our nation's future - The criminal justice system' in R Garside \& W McMahon (eds) Does criminal justice work? The 'right for the wrong reasons' debate (2006) 92.

12 Blair (n 11 above) 89.

13 The term 'culture' is not used in its ordinary and traditionally-exclusive sense, but as a notion that has a bearing on human rights and freedoms.

14 National Commission on Terrorist Attacks upon the United States (9/11 Commission) Report 2004 (2004) http://www.gpo.gov/fdsys/pkg/GPO-911 REPORT/pdf/GPO-911REPORT.pdf (accessed 11 February 2015).

15 It is acknowledged that several human rights treaties also provide guidance on the promotion of human rights. These are, amongst others, the International Covenant on Civil and Political Rights (1966); the International Covenant on Economic, Social and Cultural Rights (1966); the Convention on the Elimination of All Forms of Discrimination Against Women (1981); the Convention Against Torture and other Cruel, Inhuman and Degrading Treatment or Punishment (1984); the Convention on the Rights of a Child (1990); and the Convention on the Elimination of all Forms of Racial Discrimination (1981). 
leading international approach to transaction reporting is not dealt with in the UN instruments as such. The latter is or could be abstracted from the reports of certain organisations that exist outside of the UN. These are, amongst others, the Organisation for Economic Co-operation and Development (OECD), ${ }^{16}$ the Financial Action Task Force (FATF) $)^{17}$ and the International Monetary Fund (IMF). ${ }^{18}$ It is submitted that an appropriate scheme to report transactions is one that is founded on or accepts the importance of a human rights culture. Consequently, the UN human rights framework becomes essential. In studying transaction reporting in an environment where human rights are promoted, the article is divided into four sections. The first section examines the relevant UN human rights measures. This investigation is made with a view to weighing up their significance to an anti-terrorism paradigm. The second section studies the general scheme of transaction reporting. This study focuses on the approach to transaction reporting that is adopted by, amongst others, South Africa. Thirdly, the approach is evaluated and tested against the background of the need to protect human rights. The UN human rights measures and related instruments or treaties are used to undertake such a test or evaluation. The fourth section concludes the article and identifies the strengths and weaknesses of current approaches to transaction reporting. Further, it recommends measures to improve the identified weakened areas, and an attempt is made to propose a framework that strikes a balance between transaction reporting and the protection of human rights.

\section{Human rights measures}

\subsection{Overview}

Measures to protect human rights are a culmination of efforts by leaders around the globe. These measures particularly espouse and promote the idea of peace and security. Peace and security are

16 The OECD was established in 1948. It provides a forum in which governments can work together to share experiences and seek solutions to common problems. See OECD 'What we do and how' http://www.oecd.org/about/whatwedoandhow/ (accessed 15 September 2015).

17 The FATF is an inter-governmental body established in 1989. It sets standards and promotes the effective implementation of legal, regulatory and operational measures for combating money laundering, terrorist financing and other related threats to the integrity of the international financial system. It currently has about 34 member countries (including South Africa) and two observer countries. See FATF 'Who we are' http://www.fatf-gafi.org/pages/aboutus/whoweare/ (accessed 15 September 2015).

18 The IMF is the brain child of the UN. It was established during 1944. It has about 188 member countries. South Africa is one of the members. See IMF 'Why the IMF was created and why?' http://www.imf.org/external/about.htm (accessed 14 September 2015). 
essential for the 'survival of man (or woman)' ${ }^{19}$ In addition, they are relevant to ${ }^{20}$

[preconditions for] survival, namely with an order worthy of the designation 'peace' [and security] not only because it guarantees the prevention of war but also because it makes it possible the development of human dignity and basic rights.

The association of peace and security with human dignity and basic rights is indispensable to the general UN framework for human rights protection. For example, the failure of the League of Nations to achieve one of its mandates, that is, to promote international peace and security, resulted in efforts to restore stability and peace in the world. The UN Atlantic Charter of 1941 is but one such an effort. This Charter sought to ensure, amongst others, that 'all men in all lands may live their lives in freedom from fear and want'. ${ }^{21}$ This freedom from fear and want was to be achieved by guaranteeing the free movement of civilians and abandoning the use of force. ${ }^{22}$ These efforts, furthermore, were followed by the introduction of the UN Charter of Rights. The UN Charter provides, amongst others: ${ }^{23}$

[We] the peoples of the United Nations, [are] determined to reaffirm faith in fundamental human rights, in the dignity and the worth of the human person, in the equal rights of men and women and of the nations large and small.

The issue related to the 'dignity and the worth of the human person' requires some elaboration. It is indeed true that human dignity is the precondition for or the basis of peace and security. ${ }^{24}$ It is not an extra benefit which is 'conferred upon a person by social contract or positive law'. ${ }^{25}$ Rather, it is inherent in a person ${ }^{26}$ and granted to the latter at birth. ${ }^{27}$ In the former sense, human dignity is the starting point for 'humanness'. 28 In other words, it guarantees the worth of a human person or a fundamental human significance. ${ }^{29}$ In addition, human dignity is a specific 'cultural understanding of the inner moral

19 K Kaiser 'Problems and tasks of peace and conflict research' (1973) Law and State 17.

20 Kaiser (n 19 above) 7.

21 Principle 6 of the Atlantic Charter.

22 Principle 7 read with principle 8 of the Atlantic Charter.

23 Preamble to the UN Charter.

24 EK Quashigah 'Protection of human rights in the changing international scene Prospects in sub-Saharan Africa' (1994) 6 African Journal of International and Comparative Law 9394.

25 C Smith What is a person? Rethinking humanity, social life, and the moral good from the person up (2010) 434

26 See Preamble to the Universal Declaration.

27 RE Howard 'Dignity, community, and human rights' in AA An-Na'im (ed) Human rights in cross-cultural perspectives: A quest for consensus (1992) 83.

28 National Coalition for Gay and Lesbian Equality $v$ Minister of Justice 1999 (1) SA 6 (CC) 60-61 and S v Makwanyane 1995 (3) SA 391 (CC) 144.

29 National Coalition for Gay and Lesbian Equality (n 28 above) 60-61 and Dawood v Minister of Home Affairs 2000 (3) SA 936 (CC) 35. 
worth of the human person and his or her political relations with society'. ${ }^{30}$ With this in mind, the UN Charter enjoins UN member states to undertake particular tasks. These tasks are designed to preserve the dignity and/or the worth of the human person. They relate to a practice of tolerance and of living together as good neighbours; unity of strength in order to maintain international peace and security; ensuring that armed forces are not used, save in the common interest; and to employ international machinery for the promotion of the economic and social advancement of all peoples. ${ }^{31}$

It is important to note that the UN human rights measures were prepared immediately after World War II. Accordingly, initially these measures had particular relevance to the prevention of war or the use of armed forces. In the recent past, the measures have become more important in the fight against other wrongs. Examples of these wrongs include terrorism, terrorist financing and money laundering. ${ }^{32}$

\subsection{Fundamental human rights and anti-terrorism measures}

\subsubsection{Overview}

The need to suppress terrorism has long been a province of international legal jurisprudence. Between 1934 and 1937, the League of Nations ${ }^{33}$ already had devised measures to combat terrorism. The mechanisms were embodied in the League's Convention for the Prevention and Punishment of Terrorism. ${ }^{34}$ The 1937 Convention had far-reaching consequences. It criminalised terrorism and enjoined countries to fight against the scourge of terrorism. ${ }^{35}$ However, the impact of these measures was tarnished by the League's failure to publish the 1937 Convention. Following the League's demise in 1946, the UN took steps towards combating the plague of terrorism.

30 Howard (n 27 above) 83.

31 Preamble to the UN Charter.

32 The term 'money laundering' is associated with 'dirty money' (IL van Jaarsveld 'Mimicking sisyphus? - An evaluation of the Know Your Customer Policy' (2006) 27 Obiter 230-232). The dirtiness of money is often linked to the illicit manner in which the money was acquired or obtained (M Bond \& $G$ Thornton 'Money laundering' (1994) Accountants Digest 6-7). Therefore, money laundering can be said to mean a process of concealing illegal money or assets so that the money or assets appear to have been derived using genuine or legal means ( $J$ Madinger Money laundering: A guide for criminal investigators (1996) 6).

33 The League was an intergovernmental organisation founded or established immediately after World War I. One of the League's main aims was to promote international co-operation and to achieve international peace and security by the acceptance of obligations not to resort to war.

34 The League 'Convention for the prevention and punishment of terrorism' (1937) http://www.cfr.org/terrorism-and-the-law/league-nations-convention-preventionpunishment-terrorism/p24778 (accessed 18 August 2014) (1937 Convention). Saul avers that the 1937 Convention marks the League's response to the assassination of King Alexander I of Yugoslavia (B Saul 'The legal response of the League of Nations to terrorism' (2006) 4 Journal of International Criminal Justice 79. 80).

35 Arts 1 \& 21937 Convention. 
Consequently, the Convention on Offences and Certain other Acts Committed on Board Aircraft (Tokyo Convention) was adopted in 1963. ${ }^{36}$ The Tokyo Convention criminalised the 'unlawful seizure of an aircraft, ${ }^{37}$ in cases where such seizure resulted in the wrongful control of the aircraft in flight. ${ }^{38}$ Both the 1937 and the Tokyo Conventions treated terrorism as an international crime.

The global nature of terrorism is also identified in the International Convention for the Suppression of the Financing of Terrorism. ${ }^{39}$ Broadly speaking, the UN Anti-Terrorism Convention regards the fight against terrorism as a necessary phenomenon towards achieving international peace and security. ${ }^{40}$ For this reason, countries are encouraged to, amongst others, criminalise terrorism ${ }^{41}$ and to establish mechanisms within their domestic settings to identify, detect and freeze or seize funds used or allocated for use for purposes of terrorism. ${ }^{42}$ In addition, the UN General Assembly issued its universal strategy to counter terrorism. ${ }^{43}$ The Global Counter-Terrorism Strategy posits that terrorism is a global crime which requires a worldwide and integrated response. ${ }^{44}$ Such a response, it is argued, should, however, promote the need to ensure respect for fundamental human rights. ${ }^{45}$ The Global Counter-Terrorism Strategy was followed by the passing of a Resolution by the UN Security Council in August $2011 .{ }^{46}$ This Resolution reiterates the UN stance regarding the importance of uplifting fundamental human rights in the fight against

36 UN 'Convention on offences and certain other acts committed on board aircraft' (1963) http://treaties.un.org/doc/db/Terrorism/Conv1-english.pdf (accessed 12 February 2015) (Tokyo Convention).

37 Ch IV Tokyo Convention.

38 Art 11(1) Tokyo Convention. In terms of the Tokyo Convention, an aircraft is considered to be in flight from the moment when power is applied for the purpose of take-off until the moment the landing run ends (art 1(3) Tokyo Convention). For the meaning of the term 'in flight', see art 3(1) of the UN Convention for the Suppression of Unlawful Seizure of Aircrafts (1970) http:// www.oas.org/juridico/MLA/en/Treaties/en_Conve_Suppre_Unlaw_Seiz_Aircr_Sig_ The_Hague_1970.pdf (accessed 13 February 2015).

39 The UN 'International Convention for the Suppression of the Financing of Terrorism' (1999) http://www.un.org/law/cod/finterr.htm (accessed 13 February 2015) (UN Anti-Terrorism Convention).

40 Preamble to the UN Anti-Terrorism Convention; UN General Assembly 'Resolution on Measures to Eliminate International Terrorism' (1994) http://www.ref world. $\mathrm{org} / \mathrm{cgi}$-bin/texis/vtx/rwmain?page=topic\&tocid $=4565 \mathrm{c} 22538 \&$ toid $=459 \mathrm{a} 87252$ \&publisher $=\&$ type $=$ RESOLUTION $\&$ coi $=\& d o c i d=3$ b00f3171 $c \&$ skip $=0$ (accessed 12 February 2015); UN Security Council 'Declaration on the global effort to combat terrorism' (2001) http://www.un.org/ga/search/view_doc.asp? symbol=S/ RES/1377(2001) (accessed 13 February 2015).

41 Art 4 UN Anti-Terrorism Convention.

42 Art 8(1) UN Anti-Terrorism Convention.

43 UN General Assembly 'Global counter-terrorism strategy - Activities of the United Nations system in implementing the strategy' (2012) https://www.un.org/en/ terrorism/ctitf/pdfs/A\%2066\%20762\%20English.pdf (accessed 13 February 2015).

44 UN General Assembly ( $\mathrm{n} 43$ above).

45 As above.

46 A/RES/60/288. 
terrorism. ${ }^{47}$ More specifically, it encourages countries to recognise and accept that anti-terrorism measures and the maintenance of human rights are not contradictory objectives. Conversely, antiterrorism measures and the maintenance of human rights are 'complimentary and mutually-reinforcing' goals. ${ }^{48}$ Therefore, measures to deter terrorism can operate effectively only in environments that respect and safeguard human rights. ${ }^{49}$

Outside of these UN instruments is to be found, inter alia, an intergovernmental body that is referred to as the Financial Action Task Force (FATF). The FATF has played a meaningful role in providing content to the need to prevent terrorism. It adopted a number of recommendations on 16 February 2012 in order to assist member states to identify risks and to develop policies and domestic coordination; to pursue terrorist financing and the financing of proliferation; to apply preventive measures for the financial sector and other designated sectors; to establish powers and responsibilities for the competent authorities, for example investigative, law enforcement and supervisory authorities and other institutional measures; to enhance the transparency and availability of beneficial ownership information of legal persons and arrangements; and to facilitate international co-operation. ${ }^{50}$ Accordingly, it enjoins member states not only to criminalise terrorism, but to prevent and suppress terrorism. ${ }^{51}$

\subsubsection{Human rights and terrorism}

The view that anti-terrorism measures and the maintenance of human rights are 'complimentary and mutually-reinforcing' goals is supported by the former UN Secretary-General, Kofi Annan. In particular, Annan comments as follows: ${ }^{52}$

[Human rights law] makes ample provision for strong counter-terrorism action, even in the most exceptional circumstances ... upholding human rights is not merely compatible with a successful counter-terrorism strategy. It is an essential element in it.

\footnotetext{
47 As above.

48 As above. See also BJ Goold \& L Lazaraus 'Security and human rights: The search for a language of reconciliation' in BJ Goold \& L Lazarus Security and human rights (2007) 1; NT Katyal \& LH Tribe 'Waging war, deciding guilt - Trying the military tribunals' (2002) 111 Yale Law Journal 1259-1260.

$49 \mathrm{~A} / \mathrm{RES} / 60 / 288$.

50 FATF 'International standards on combating money-laundering and the financing of terrorism and proliferation' (2012) http://www.fatf-gafi.org/media/fatf/ documents/recommendations/pdfs/FATF_Recommendations.pdf (accessed 15 September 2015).

51 See Recommendations 5 and 6 of the FATF Recommendations.

52 K Annan Keynote address to the Closing Plenary of the International Summit on Democracy, Terrorism and Security, Madrid, Spain, 10 March 2005.
} 
It is argued that various rights may be encroached upon during the fight against terrorism. These include the inherent right to life; ${ }^{53}$ the right not to be subjected to torture or to cruel, inhuman or degrading treatment or punishment; ${ }^{54}$ the right to liberty and security of person; ${ }^{55}$ and the right not to be subjected to arbitrary or unlawful interference with a person's privacy, home or correspondence, or to unlawful attacks on a person's honour and reputation. ${ }^{56}$

Because of this, it becomes necessary to establish human rights institutions that are designed to alleviate the scale of this potential encroachment. The most notable are the UN Human Rights Council, ${ }^{57}$ the Economic and Social Council; the Sub-Commission on the Prevention of Discrimination and Protection of Minorities; the Commission on the Status of Women; the UN High Commissioner for Human Rights; and the Office of the High Commissioner for Human Rights (OHCHR). This article discusses the activities and functions of the OHCHR.

The OHCHR acts as the principal human rights office of the UN. ${ }^{58} \mathrm{It}$ was established following the recommendations by delegates of about 171 countries at the World Conference on Human Rights in Vienna in 1993. Subsequent to these recommendations, the UN General Assembly on 20 December 1993 passed Resolution 48/141 for its establishment. The $\mathrm{OHCHR}$ is responsible for promoting and protecting the successful enjoyment of civil, cultural, economic, political, social and developmental rights; providing consultative services, technical and monetary assistance on human rights; coordinating the UN's education and public information programmes on human rights; playing a significant role in removing the obstacles to the full realisation of human rights and preventing continuing human rights violations; engaging in a dialogue with governments in order to guarantee respect for human rights; enhancing international co-operation for the promotion and protection of human rights; coordinating human rights promotion and protection activities throughout the UN system; and rationalising, adapting, strengthening and streamlining the UN machineries that relate to human rights. Furthermore, its objectives are to promote and protect fundamental human rights; to lead global human rights efforts; to provide a forum for identifying, highlighting and developing responses to human rights challenges; and to act as the focal point of human rights

53 Art 3 Universal Declaration. See also art 6(1) of the International Covenant on Civil and Political Rights of 19 December 1966 (ICCPR).

54 Art 5 Universal Declaration and art 7 ICCPR.

55 Art 3 Universal Declaration and art 9(1) ICCPR.

56 Art 12 Universal Declaration and art 17(1) ICCPR.

57 The UN Human Rights Commission was established in 2006. It replaces the UN Commission on Human Rights.

58 OHCHR 'Who we are?' http://www.ohchr.org/EN/AboutUs/Pages/WhoWeAre.aspx (accessed 10 September 2014). 
research, education, public information and advocacy activities in the UN system. ${ }^{59}$

The OHCHR relies on surveys in order to fulfil its responsibility as a supervisory body. These surveys are intended to assess a country's standing in relation to the promotion of a culture of fundamental human rights. Furthermore, surveys compel the establishment of a paradigm that alleviates terrorism, on the one hand, and mainstream a culture that promotes and protects fundamental human rights, on the other. ${ }^{60}$

In summary, human rights are the bedrock of the fight against terrorism. In particular, the relationship between human rights and anti-terrorism measures promotes the establishment of a framework which uplifts respect for the rule of law, good governance and human rights. ${ }^{61}$ This framework does not repress human rights and the rule of law, ${ }^{62}$ but encourages debate for or against existing measures against terrorism, including transaction reporting measures. ${ }^{63}$ However, it is important to note that the UN accepts that there is no such a thing as limitless rights. This can be deduced from certain provisions of, inter alia, the International Covenant on Civil and Political Rights (ICCPR). For instance, article 17 of the the ICCPR provides protection to a victim of 'arbitrary or unlawful interference with his (or her) privacy, family, home or correspondence'. Accordingly, interference alone does not entitle a victim to protection under article 17. The protection arises in cases where it is alleged that the interference is arbitrary or unlawful.

This then brings us to the next issue regarding transaction reporting. The section below delves into the meaning and working of transaction reporting.

\section{Transaction reporting}

\subsection{Overview}

Transaction reporting is possible in environments where, inter alia, a suitable transaction recording procedure exists. ${ }^{64}$ Transaction recording is an old phenomenon, developed as early as $3200 \mathrm{BC}$. This

59 OHCHR (n 58 above).

60 UN Human Rights Council 'Promotion and protection of all human rights, civil, political, economic, social and cultural rights, including the right to development' (2009) http://www2.ohchr.org/english/issues/trafficking/docs/HRC-10-16.pdf (accessed 10 February 2015).

61 OHCHR Fact Sheet 32 (n 6 above).

62 As above.

63 As above.

64 WH Muller et al Anti-money laundering: International law and practice (2007) 429; MC Bassiouni \& DS Gualtieri 'International and national responses to the globalisation of money laundering' in EU Savona (ed) Responding to money laundering: International perspectives (1997) 137. 
method was used to account for or calculate animals and other goods. With this method, a simplified representation of the animal or goods was drawn on the bulges of drenched terracotta. Afterwards, a resembling mark was made for the number counted and recorded. The terracotta would then be allowed to swelter in the sun and would thus become an enduring document. ${ }^{65}$ Eventually, ancient Egypt and Rome developed their own methods of recording. In ancient Egypt, recording was carried out by a particular influential faction (the scribes). The scribes used raised edges of capsules or tablets for recording purposes. In Rome, a method of recording, referred to as shorthand, was used. Shorthand developed as a result of the necessity to keep up with the speed of spoken words. It relied on notes and symbols as equivalents for phrases or sentences. Swiftness and precision were the fundamental features of this system of recording. ${ }^{66}$

The success of record keeping in the periods mentioned above contributed to the adoption of this system in anti-terrorism schemes. The importance hereof specifically led to transaction recording being adopted to support anti-terrorism paradigms. In anti-terrorism schemes, transaction recording supports the undertaking of transaction reporting schemes. Specifically, they guarantee that 'a transaction, or a series of transactions, can be reconstructed during an investigation, clearly indicating not only what had transpired, but also who was 'involved' in it. ${ }^{67}$ In addition, they are performed as part of the customer due diligence (CDD) or know-your-customer (KYC) process. The meaning of CDD becomes clearer when reference is made to the terms 'due' and 'diligence'. On the one hand, the notion of 'due' denotes something that is definite or expected. ${ }^{68}$ On the other, the concept of 'diligence' connotes a vigilant and methodical work or exertion. ${ }^{69}$ Within the context of anti-terrorism, 'due diligence' means a sensible and methodical process of appraising

65 History World 'History of writing' http://www.historyworld.net/wrldhis/ PlainTextHistories.asp? historyid=ab33 (accessed 24 February 2015).

66 TC Parkin Old age in Roman world: A cultural and social history (2003) 182-183. This method was followed in Athens, Greece, in the year 330 BC. The Athenian method encompassed the preserving of information or records in the Metroon, that is, the holy mother of the Gods (see JP Sickinger Public records and the archives in classical Athens (1999) 1-2).

67 Financial Intelligence Centre (FIC) 'Joint statement - Clarification on the obligations of accountable institutions on verifying client identities and record keeping' (2009) https://www.fic.gov.za/DownloadContent/NEWS/PRESSRELEASE/ JOINT\%20STATEMENT\%20Verifying\%20and\%20recording\%20keep\%20of\%20cli ent\%20identities\%20trkcm.pdf (accessed 7 February 2015).

68 AS Hornby et al Oxford advanced learner's dictionary of current English (2005) 474.

69 Hornby et al (n 68 above) 425. 
personal information ${ }^{70}$ or data $^{71}$ in order to classify divergent risks to an anticipated relationship or relationships. ${ }^{72}$ In other words, it facilitates a process of identifying whether a transaction or transactions is or are in keeping with the required policies, procedures or methodologies or not. ${ }^{73}$ The CDD or KYC process is performed by establishing and verifying the identity of a person. ${ }^{74}$ Firstly, the establishment practice is satisfied by the furnishing or disclosing of sensitive or personal information to a financial institution. ${ }^{75}$ The information to be furnished or disclosed to a financial institution includes a person's full names, date of birth, identity number, income tax registration number (if applicable) and residential address. ${ }^{76}$ The furnishing or disclosing of information should enable such an institution to make an informed decision on whether to accept a person to its business or not. 77 The Financial Intelligence Centre Act (FICA) does not provide a definition of the term 'business' for antiterrorism purposes. For that reason, its meaning has to be sought outside of FICA. In Standard General Insurance Company v Hennop, the court stated that 'anything which occupies the time and attention and labour of a man for the purpose of profit is [a] business'. ${ }^{78}$ This 'anything' can be a commercial activity or any other institution. ${ }^{79}$ In addition, the disclosure of information may be made by the person himself or herself or on his or her behalf by his or her agent or guardian. ${ }^{80}$ Exceptions are made in respect of minors, the mentally

70 The term 'information' means a 'piece of news with a meaning for the recipient; its assimilation usually causes a change within the recipient' ( $U$ Sieber 'The emergence of information law - Object and characteristics of a new legal order' in E Lederman \& R Shapira (eds) Law, information and information technology (2001) 10-11.

71 The word 'data' appears to have different meanings. Firstly, sec 1 of the NonProliferation of Weapons of Mass Destruction Act 87 of 1993 stipulates that data includes any data or information of a technical or other nature as well as blueprints, diagrams, plans, models, formulae, engineering designs, specifications, manuals and instructions, whether written or recorded by means of any electronic, magnetic or optical process. Secondly, sec 1 of the Electronic Communications and Transactions Act 25 of 2002 defines data as the electronic representation of information in any form. The word 'any form' is not defined in the ECT Act. For purposes of this study, the word 'any form' will mean automated or non-automated form.

72 Indac Electronics (Pty) Ltd v Volkskas Bank Ltd 1992 (1) All SA 411 (A) 413-416.

73 LS Spedding Due diligence and corporate governance (2004) 3. See also sec 21 of the Financial Intelligence Centre Act 38 of 2001 (FICA).

74 Sec 21(1)(a) FICA. A reference to a 'person' means a person who or a business which wishes to or has established a business relationship or concluded a transaction or single transaction with a financial institution, eg a bank.

75 Regulation 3 of the FICA Regulations of GN R1595 in GG 24176 of 20 December 2002 (FICA Regulations).

76 Regulation 3(1)(a)-(e) of the FICA Regulations.

77 Proc R715 in GG 27803 of 18 July 2005 (FIC Guidance Note 3) 15.

781954 (4) 560 (A) 565.

79 Proc R301 in GG 30873 of 14 March 2008 (FIC Guidance Note 4).

80 Secs 21(1)(a), (b) \& (c) FICA. 
disabled, prodigals and insolvent persons. ${ }^{81}$ Secondly, the verification process implies comparing the information disclosed during the establishment process to other documents serving the verification process. ${ }^{82}$ For example, a person's income tax registration number may be compared to the number appearing in a document issued by the South African Reserve Bank. ${ }^{83}$ Furthermore, a person's full names, date of birth and identity number may be compared to a person's official identification document (ID), ${ }^{84}$ alternatively to a valid, current and unexpired document, ${ }^{85}$ for example a valid driver's licence or an official passport. ${ }^{86}$

The discussion above indicates that transaction reporting follow transaction recording. Transaction recording is an old phenomenon used to compute certain information or particulars. It also illustrates that transaction recording facilitates a process of reporting transactions. Therefore, the achievements that it has enjoyed in computing information have led to it being adopted in order to assist in the fight against terrorism. As a consequence, countries around the globe have realised the need to establish measures related to transaction reporting. In this article, the South African approach to transaction reporting is examined. South Africa follows frameworks to transaction reporting developed internationally. Of particular interest is the model created by the FATF and some provisions of the United Kingdom's Terrorism Act ${ }^{87}$ and UK Regulations.

\subsection{South African approach}

The measures that South Africa adopts in order to deter terrorism can be traced back to as far as 1950, embodied in legislation such as the Suppression of Communism Act, ${ }^{88}$ the Unlawful Organisation Act, ${ }^{89}$ the General Law Amendment Act, ${ }^{90}$ the Terrorism Act ${ }^{91}$ and the

81 Sec 21(1)(c) FICA. For an extensive reading on the capacity to conclude contracts by these persons, see J Heaton 'Status and capacity: The determining factors' in B van Heerden et al Boberg's: law of persons and the family (1999) 74-75. For further reading regarding the effect of insanity and prodigality on a person's capacity to act, see Phil Morkel Bpk v Niemand 1970 (3) SA 455 (K); Ex Parter Klopper: In Re Klopper 1961 (3) SA 803 (T); Lange v Lange 1945 AD 332; Pienaar $v$ Pienaar's Curator 1930 OPD 171

82 Regulation 4 FICA Regulations.

83 Regulation 4(2) FICA Regulations.

84 Regulation 4(1)(a)(i) FICA Regulations. An ID, for purposes of the establishment and verification process in South Africa, refers to a green bar-coded identity document (sec 1 of the Regulation of the Interception of Communication and Provision of Communication-Related Information Act 70 of 2002).

85 Regulation 4(1)(a)(ii)(aa)-(dd) FICA Regulations.

86 FIC Guidance Note 313.

87 The United Kingdom Terrorism Act of 2000.

88 Suppression of Communism Act 44 of 1950.

89 Unlawful Organisation Act 34 of 1960.

90 General Law Amendment Act 37 of 1963.

91 Terrorism Act 83 of 1967. 
Internal Security Act. ${ }^{92}$ They relied on the principle of salus reipublicae suprema lex. This principle was based on the premise that the safety and wellbeing of the state was the supreme or highest law. ${ }^{93}$ For purposes of anti-terrorism, the salus reipublicae suprema lex principle afforded the state the power to, mainly, disregard the ordinary safeguards of human rights, ${ }^{94}$ relying on the fact that the 'highest or supreme law' demands such curtailment. ${ }^{95}$ However, this position changed when the first democratic South African Constitution was adopted in 1994, establishing the supremacy of the Constitution, ${ }^{96}$ leading to the abandonment of the salus reipublicae suprema lex principle. The Constitution, 1996 restricts the powers of government, and promotes adherence to different sets of rules regarding the protection of human rights. ${ }^{97}$ The Constitution further encourages meaningful obedience to particular democratic values, including human dignity, the achievement of equality and the advancement of human rights and freedoms. ${ }^{98}$ The coming into effect of the Constitution compelled the legislature to model its laws, including laws that restrain terrorism, ${ }^{99}$ to be in line with the Constitution. 100

FICA was promulgated with a view to responding to the scourge of terrorism. Sections 28, 28A and 29 of FICA specifically regulate transaction reporting under the new constitutional order. It would appear that the approach to transaction reporting in terms of these sections differs in a number of respects. For example, section 28 deals with the reporting of cash transactions which are above a certain prescribed limit (R24 999,99). ${ }^{101}$ For purposes of section 28, the term 'cash' has a specific meaning. Cash excludes negotiable instruments, the transfer of funds by means of a bank cheque or bank draft, an electronic funds transfer, wire transfer or any other non-physical transfer of cash. ${ }^{102}$ Section $28 \mathrm{~A}$ covers the reporting of property which is associated with terrorism or terrorism-related activities. This 'property' may be in the form of 'money or any other movable, immovable, corporeal or incorporeal thing and includes any rights, privileges, claims and securities and any interest therein and all proceeds thereof'. ${ }^{103}$ However, section 29 provides a broad

92 Internal Security Act 74 of 1982.

93 DA Basson \& HE Viljoen South African constitutional law (1988) 419; HI Flower Roman republics (2010) 147.

94 Flower (n 93 above) 147

95 Krohn v Minister of Defence 1915 AD 191197.

96 Sec 2 Constitution of the Republic of South Africa, 1996

97 Ch 2 South African Constitution.

98 Sec 1(a) South African Constitution. For further reading on the other values, see secs $1(b)-(d)$ of the Constitution.

99 FICA, Protection of Constitutional Democracy against Terrorist and Related Activities Act 33 of 2004 (PCDTRA) and the Prevention of Organised Crime Act 121 of 1998 (POCA).

100 Sec 2 South African Constitution. See also sec 36 of the Constitution.

101 Regulation 22B FICA Regulations.

102 FIC Guidance Note 5.

103 Sec 1 (xvi) POCA. See also sec $1(x x)$ of the PCDTRA. 
framework for transaction reporting. Essentially, it follows the same approach as article 18 of the UN Anti-Terrorism Convention. This Convention specifically encourages financial institutions to design special identification measures to unusual, suspicious, complex and unusually large transactions. ${ }^{104}$ As soon as this identification process has been completed, a description of these transactions must be reported or furnished to the competent authorities. ${ }^{105}$ Also, transaction reporting in terms of section 29 of FICA is required to be made to the Financial Intelligence Centre (FIC). ${ }^{106}$ Various persons are enjoined to report transactions. These persons are individuals who carry on a business, individuals in charge of a business, individuals who manage a business or individuals employed by a business. ${ }^{107}$ The persons mentioned must know or suspect the existence of certain facts.

The terms 'know' and 'suspect' for purposes of transaction reporting require additional elaboration. Firstly, the term ' $k$ now' means the presence of definite awareness. In particular, a person has knowledge of a fact if such a person has a genuine understanding of that fact, or if it is proved that such a person believes that there is a reasonable possibility of the existence of a fact, and that person fails to obtain information to confirm or refute the existence of such a fact. ${ }^{108}$ The requisite knowledge is not only confined to the 'mental state of awareness [that is] produced by personal participation' of a person in a crime or terrorism, ${ }^{109}$ neither is it only associated with any 'information derived' from such a person. ${ }^{110}$ However, it encompasses an assurance or conviction that a particular circumstance, that is, a suspicious transaction, exists. ${ }^{111}$ The latter may be gleaned from examining the mental state (mens rea) of a person at the time the crime (terrorism) was committed. ${ }^{112}$ Secondly, a suspicion is formed or established without the existence of clearly-defined or definable grounds. ${ }^{113}$ It particularly means 'a state of conjecture or surmise where proof is lacking; I suspect but I cannot prove'.114 It arises or ensues 'at or near the starting point of an investigation of which [the]

104 Art 18(b) UN Anti-terrorism Convention.

105 Art 18(b)(iii) UN Anti-terrorism Convention.

106 The FIC is an institution which is established in terms of sec 2 of FICA. The FIC is established to respond to recommendation 26 of the FATF Recommendations. The FIC is the South African intelligence unit that provides support in the fight against terrorism.

107 Sec 29(1) FICA.

108 Sec 1(2) FICA.

109 R v Patz 1946 AD 845857.

110 Patz (n 109 above) 857.

111 As above.

112 SVV Construction v Attorneys, Notaries \& Conveyance Fidelity Guarantee Fund 1993 (2) SA 577 (C) $585 \mathrm{~F}-585 \mathrm{H}$.

113 Duncan $v$ Minister of Law and Order 1986 (2) SA 805 (A) 819l; Minister of Law and Order v Kader 1991 (1) SA 41 (A) 50H-50].

114 Shabaan Bin Hussein v Chong Fook Kam 1970 AC 942 (PC) 948(B); Powell NO v Van Der Merwe NO 2005 (5) SA 62 (SCA). 
obtaining of prima facie proof is the end'. ${ }^{115}$ However, it is required that a degree of satisfaction, which extends beyond a mere speculation, should exist to justify or support the suspicion. ${ }^{116}$ In cases where knowledge or a suspicion cannot readily be ascertained, some form of awareness of the facts is extrapolated. Accordingly, a three-stage analysis is generally undertaken to establish the existence of the requisite knowledge or suspicion. This analysis relates to whether or not a person is actually aware of something; where circumstances arise wherein a person can reasonably be expected to be aware of something; or where circumstances arise wherein a person can reasonably be expected to suspect the existences of something. ${ }^{117}$

The pertinent facts that must be reported include, inter alia, transactions that facilitate or are likely to facilitate the proceeds of unlawful activities ${ }^{118}$ or are connected to terrorism or terrorist-related activities; transactions that have no apparent or noticeable business or lawful purpose; transactions that are conducted for the purpose of avoiding or evading reporting duties; transactions that may be relevant to the investigation of an evasion or attempted evasion of a duty to pay tax, duties or levies imposed by legislation; or transactions that relate to an offence which is connected to the financing of terrorism and/or terrorist-related activities. ${ }^{119}$ Generally, a suspicious and unusual transaction report (STR) has to be compiled. ${ }^{120}$ The STR sets out the information or facts that should be reported. In particular, it must include the particulars of a person or a business making the report; ${ }^{121}$ detailed information related to the transactions that are being reported; ${ }^{122}$ details of the account involved in concluding the transaction; ${ }^{123}$ the particulars of a person (natural or legal) on whose behalf the transaction is concluded:124 and the particulars of a person (natural or legal) who acts on behalf of another. ${ }^{125}$ Furthermore, the STR must include detailed information relating to the date and time of the transaction; if a series of transactions, the period over which the

115 Shabaan Bin Hussein (n 114 above) 948(B).

116 Commissioner for Corporate Affairs v Guardian Investments [1984] VR 1019. See also Walsh v Loughman [1992] 2 VR 351.

117 FIC Guidance Note 410.

118 Sec 1 of POCA defines the term 'proceeds of unlawful activities' as any property or service, advantage, benefit or reward that was derived, received or retained, directly or indirectly, in the Republic or elsewhere, at any time before or after the commencement of this Act, in connection with or as a result of any unlawful activity carried on by any person, and includes any property representing property so derived.

119 Secs 29(1)(b)(i)-(v) FICA. See FIC Guidance Note 4 15, for the indicators of suspicious and unusual transactions.

120 GN R456 in GG 27580 of 20 May 2005 (2005 FICA Regulations).

121 Regulation 23(1) 2005 FICA Regulations

122 Regulation 23(2) 2005 FICA Regulations.

123 Regulation 23(3) 2005 FICA Regulations.

124 Regulation 23(4) 2005 FICA Regulations.

125 Regulation 23(5) 2005 FICA Regulations. 
transactions were carried out; a description of the type of transaction; the manner in which the transactions were carried out; a description of the type of funds or cash involved in the transactions (if transactions involved funds or cash); a description of the type of property and all identifying characteristics of the property (if transactions involved property); the amount of funds or cash, or the estimated value of the property involved in the transactions; the currency in which the transactions were conducted; the manner in which the funds, cash or property were disposed of; the amount of the disposition of the funds or cash; the value for which the property was disposed of; the currency in which the funds or cash were disposed of and the currency used in the disposition of the property (if funds, cash or property involved in the transactions were disposed of); if another institution or person was involved in the transaction or series of transactions, the name of the other institution and the number of any account at the other institution involved in the transactions; the name and identifying particulars, for instance the address, the exclusive or unique number or code of the branch or office where the transactions were concluded; the purpose of the transactions; and the remarks, comments or explanation made or given by the person concluding the transactions. ${ }^{126}$ Lastly, the STR must encapsulate details such as the account number; the name and identifying particulars of the branch where the account is held; the account type; the account holder's name; the date on which the account was opened; in cases where the account had been closed, the date of its closure and the name of the person who gave the instruction for its closure; the highest amount paid into and out of the account; the number of payments made into and out of the account; the balance in the account before concluding the transactions; the balance in the account on the date of drawing up the STR; the status of the account before the reported transactions were concluded; any activity (in the preceding 180 days) that had been considered for reporting; and the reference numbers allocated by the FIC. ${ }^{127}$

It is important to note that no duty of secrecy or confidentiality or any other restriction is required to be exercised during transaction reporting. ${ }^{128}$ This means that a financial institution is absolved of its obligations pertaining to the observance of secrecy and confidentiality in these cases. ${ }^{129}$ Such absolution also excludes the restrictions that are normally accorded to information which is protected by legal professional privilege. ${ }^{130}$ This relates, amongst others, to the protection which is usually granted to information as between an attorney and client and which is disclosed by such a client for purposes of legal advice or litigation, or between an attorney and

126 Regulation 23(2)(a)(I) 2005 FICA Regulations.

127 Regulation 23(3)(a)-(o) 2005 FICA Regulations.

128 Sec 37(1) FICA.

129 As above.

130 Sec 37(2) FICA. 
third party for purposes of pending, contemplated or already commenced litigation. ${ }^{13}$

Having considered the above-mentioned, it is submitted that South Africa has adopted an approach to the fight against terrorism which is receptive to the need to protect and promote human rights. The human rights guarantees that are enumerated in the Constitution inadvertently promote the reconciliation of the need to fight terrorism with the necessity to preserve fundamental rights and freedoms. For this reason, it is expected that measures to alleviate terrorism, including the processes relating to STR, will be in keeping with these guarantees. However, it would appear that South Africa sometimes departs from the established human rights culture when dealing with terrorism. For example, the constitutional guarantees of secrecy and confidentiality do not apply during the process of STR. ${ }^{132}$ In other words, STR seems to disregard or outweighs the ordinary safeguards of human rights, for example, privacy and confidentiality. ${ }^{133}$ The aforementioned also applies, to a limited extent, to information which is furnished and/or disclosed during the course of an attorney-client relationship. . $^{134}$ Furthermore, there are cases which indicate a separation between what South Africa pronounces as its stance on human rights and that which is actually done in practice. In these cases, South Africa appears to suspend human rights until the act of terrorism has been dealt with. The case of Jeebhai \& Others $v$ Minister of Home Affairs \& Others ${ }^{135}$ illustrates the aforementioned. The facts of this case were briefly the following: A Pakistani national by the name of Khalid Rashid was arrested by members of the South African Police Service. The basis for the arrest was that Mr Rashid was suspected of having entered the Republic of South Africa without the necessary or legal documents authorising his stay. ${ }^{136}$ Subsequent to his arrest, $\mathrm{Mr}$ Rashid was deported to Pakistan. The circumstances under which $\mathrm{Mr}$ Rashid was deported by South Africa were suspicious. Specifically, his deportation was done in secret and carried out without following the usual procedure of placing the deportee into an approved facility or port of entry designated as such by the Minister of Home Affairs (the Lindela Repatriation Centre) pending deportation. Instead, Mr Rashid was, without informing his friends or family, handed over to the Pakistani law enforcement. ${ }^{137}$ It transpired later that Mr Rashid was wanted and sought by the Pakistani and British authorities for having links with certain 'international terrorist networks'. ${ }^{138}$ Having

131 Secs 37(2)(a) \& (b) FICA.

$132 \mathrm{Sec} 37(1)$ FICA.

133 As above.

134 Secs 37(2)(a) \& (b) FICA.

1352009 (5) SA 54 (SCA).

136 Jeebhai (n 135 above) 58 .

137 Jeebhai 59.

138 See South African Government 'Government communications on deportation of Khalid Rashid' (2006) http://www.gov.za/government-communications-depor tation-khalid-rashid (accessed 13 September 2015). 
considered these facts, the court, per Cachalia JA, stated that 'an act of deportation does not necessarily involve the loss of a deportee's liberty'. ${ }^{139}$ The loss of liberty would be justified, the court reasoned, if the act of deportation is made in a manner which safeguards the deportee's rights, that is, the right to be informed of the decision to deport, the right to appeal the decision, and the right to request that the detention be confirmed by a court warrant within 48 hours. Given the fact that there was no legal justification of the aforementioned operation by South Africa, the court stated that the whole scheme was simply a 'disguised extradition'. ${ }^{140}$ Consequently, the court held that the detention and deportation of Mr Rashid were unlawful. ${ }^{141}$

\subsection{Evaluating the STR approach}

It is submitted that the approach to transaction reporting, generally, encroaches upon certain fundamental human rights. The most obvious of these rights is a person's right not to be subjected to arbitrary or unlawful interference with his privacy, home or correspondence, or to unlawful attacks on his honour and reputation. ${ }^{142}$ Ordinarily, financial institutions owe their customers a duty to 'maintain confidentiality and secrecy'. ${ }^{143}$ This responsibility generally is exercised in relation to information or data belonging to those customers or transactions that the customers conclude during the course of the business relationship. ${ }^{144}$ Sometimes, this duty is described as the naturale of the contract between financial institutions and their customers. ${ }^{145}$ Thus, an encroachment occurs in cases where disclosure of information or transactions belonging to customers is made to third parties, for example the FIC. However, whether such encroachment preserves human rights is determined by the Constitution, namely, section 36 of the Constitution. ${ }^{146}$

Section 36 of the Constitution states that rights may be limited only in terms of law of general application to the extent that the limitation is reasonable and justifiable in an open and democratic society based on human dignity, equality and freedom. ${ }^{147}$ The requirement of 'reasonableness' and 'justifiability' does not extend to the impairment of a 'democratic functioning of society'. ${ }^{148}$ In other words, it does not necessarily translate into the negation of the rule of law, good

139 Jeebhai (n 135 above) 63.

140 Jeebhai 72.

141 Jeebhai 74.

142 Art 17(1) ICCPR.

143 WG Schulze 'Big sister is watching you - Banking confidentiality and secrecy under siege' (2001) 13 SA Mercantile Law Journal 601-603.

144 As above.

145 Abrahams v Burns 1914 CPD 452 456, Cambanis Buildings (Pty) Ltd v Gal [1983] 1 All SA 383 (NC) 392-393; Densam (Pty) Ltd v Cywilnat (Pty) Ltd [1991] 1 All SA 275 (A) 285-287.

146 Bernstein $v$ Bester NO 1996 (2) SA 751 (CC) 67.

$147 \mathrm{Sec} 36(1)$ South African Constitution.

148 OHCHR Fact Sheet 32 ( 6 above). 
governance and human rights. Conversely, it denotes the pursuit of pressing societal objectives and their impact on human rights and freedoms. ${ }^{149}$ In addition, a reference to law of general application denotes, for purposes of transaction reporting, that the law that limits secrecy and confidentiality should be sufficiently accessible. ${ }^{150}$ This accessibility must enable persons against whom transaction reporting is made to understand the extent and limits of their rights to secrecy and confidentiality. ${ }^{151}$ It must also reflect the 'norms and values of the people which it seeks to bind'. ${ }^{152}$ Furthermore, section 36 states that the limitation must take into account the nature of the right, the importance of the purpose of the limitation, the nature and extent of the limitation, the relation between the limitation and its purpose, and less restrictive means to achieve the purpose. ${ }^{153}$

Notwithstanding the aforementioned, it is argued that some of the information used for purposes of transaction reporting may be founded on unreliable data. In one case, the unreliability may stem from information that is a product of an illegal activity or operation. An example of the operation is illegal deportation, as was indicated in the case of Jeebhai. ${ }^{154}$ Another example relates to information relating to the issuing of a valid television licence. Vendors issue television licences on the basis of information recorded and/or furnished by the applicant on a required form. The information is not verified and/or subjected to a CDD process. Furthermore, the information is not subjected to a rigorous risk-based approach which is necessary in identifying, assessing and evaluating the scale of the risks posed to a financial institution. ${ }^{155}$ Therefore, the use of such a licence to establish business relationships or to conclude transactions with a customer may suppress or frustrate the entire scheme of reporting transactions. Specifically, this may result in a process of guess work whereby transactions that do not pose a threat or risk to a financial institution are regarded as suspicious and those that pose a grave risk are excluded from the list. In other instances, measures that are related to transaction reporting are open-ended and vague. For example, transaction reporting is done in cases where there is, inter alia, a suspicion that a transaction may be related to or used to finance terrorism. It is conceded that a suspicion is determined by means of subjective conjectures or surmises. ${ }^{156}$ For this reason, the open-endedness and vagueness of the suspicion generate problems. It particularly distorts the limiting processes or measures and the making

149 As above.

150 As above.

151 As above.

152 FT Abioye 'Constitution making, legitimacy and the rule of law: A comparative analysis' (2011) XLIV CILSA 5961.

$153 \operatorname{Secs} 36(1)(a)-(e)$ South African Constitution.

154 Jeebhai (n 135 above).

155 See FATF 'Guidance for a risk-based approach - The banking sector' October 2014.

156 Shabaan Bin Hussein (n 114 above) 948(B). 
of suitable proportionalities between particular fundamental human rights (namely, the right privacy and the duty of confidentiality) and the need to carry out STR. ${ }^{157}$

\section{Conclusion}

Human rights are a measure and/or a benchmark for any antiterrorism paradigm. In particular, the reconciliation of human rights with anti-terrorism promotes the establishment of a framework which uplifts respect for the rule of law, good governance and human rights. ${ }^{158}$ This framework encourages a debate for or against existing measures against terrorism. ${ }^{159}$ In this article, transaction reporting is identified as one of the essential anti-terrorism measures. Transaction reporting is part of the overall CDD process. The CDD process requires financial institutions to become 'amateur detectives' ${ }^{160}$ This entails, amongst others, the undertaking of investigations relating to the legal existence of a person, ${ }^{161}$ the identification of suspicious and unusually large transactions, and the monitoring of the pattern of concluding transactions. ${ }^{162}$ South Africa requires that STRs should be made to the FIC. In addition, the transaction reporting process must be made in respect of suspicious transactions.

It is argued that the latter approach to STR contains a number of shortcomings. These shortcomings not only relate to the fact that financial institutions are expected to become 'amateur detectives', 163 but also extend to the open-ended and vague nature of the limiting measures. For example, a suspicion is almost always the product of a subjective or individual inquiry. ${ }^{164}$ Accordingly, the determination of a suspicion 'falls short of proof' which is based on established facts or evidence. ${ }^{165}$ Therefore, the constant dependence on a suspicion as one of the bases for an STR is problematic. Specifically, such reliance hampers the process of establishing the reasonableness and justifiability of the general scheme of transaction reporting. Furthermore, the fact that a suspicion should be made by a 'reasonable person' does not render STRs unproblematic. This is so because the people who normally deal with and/or report transactions on behalf of financial institutions are employees of these institutions.

157 J Wadsley \& GA Penn The law relating to domestic banking (2000) 164-165; I Currie \& I de Waal The Bill of Tights handbook (2005) 167-168.

158 OHCHR Fact Sheet 32 (n 6 above).

159 As above.

160 Schulze (n 143 above) 606.

161 Sec 21 FICA.

162 Art 18 UN Anti-Terrorism Convention.

163 Schulze (n 143 above) 606.

164 MN Njotini 'The transaction or activity-monitoring process - An analysis of the customer due diligence systems of the United Kingdom and South Africa' (2010) 31 Obiter 570.

165 As above. 
Although these employees are expected to be trained in, amongst others, transaction reporting, ${ }^{166}$ there are currently no measures that provide for the testing of the level of their skills, and for the monitoring of their transaction reporting trends and the tools they use in STRs. Accordingly, there is a danger that these 'reasonable people' may carry out the statutory duty to report transactions by simply ticking the box (box ticking). ${ }^{167}$ The case of Jeebhai may be used as an example. This case demonstrates how 'reasonable people' sometimes conduct themselves in a manner which is unreasonable during an honest attempt to act against or to prevent terrorism and the financing of terrorism. ${ }^{168}$

It is submitted that open-ended and vague limiting provisions should be avoided when conducting STR. This can be achieved by ensuring that illogical and subjective facts are excluded from the general scheme to report transactions. The basis for this should be to ensure that STR is a justifiable limitation of a person's (customer's) rights to privacy and confidentiality. In other words, it should be reasonable in the circumstances and should uphold the guarantee that it is to meant to respond to the need to protect fundamental human rights. ${ }^{169}$ It is also submitted that the executive branch of government can play an active role in this regard. Particularly it should assist in establishing unambiguous provisions that espouse the need for transaction reporting. These provisions may be contained in guidance notes and/or other regulations. As a result, such provisions should logically and unambiguously inform the person who is affected by STR, in this case the holder of the right to secrecy and confidentiality, of the objective(s) and limits of transaction reporting, and the impact that STR has or may have on his or her rights. ${ }^{170}$

166 Regulation 27(a)-(b) FICA.

167 Regulation 27(d) of FICA for the punishments for failure to report by employees of financial institutions.

168 Jeebhai (n 135 above) 63

169 Schulze (n 143 above) 614

170 Currie \& De Waal (n 157 above) 167-168. 